\title{
A Case Study of Designing an E-Learning Electrical Engineering Course
}

\author{
http://dx.doi.org/10.3991/ijoe.v8i3.2103 \\ Sameer Khader ${ }^{1}$ and Akram Abu-aisheh ${ }^{2}$ \\ ${ }^{1}$ Palestine Polytechnic University, Hebron, Palestine \\ ${ }^{2}$ University of Hartford, West Harford, USA
}

\begin{abstract}
This paper presents a case study of designing an e-learning course in the field of electrical engineeringIndustrial automation program at Palestine Polytechnic University. The applied methodology consisting of few stages starting with formulating the major course objectives, extracting topics outcomes, design the appropriate teaching tools and storyboard, and as final stage the evaluation system is designed.
\end{abstract}

On other hand, an information communication technology (ICT) questionnaire has been designed and targeting attended in the course students with purpose evaluating student ICT knowledge, knowledge leveling, and treatment their weaknesses.

The designed topics are modified according to feedback evaluation obtained from students throughout designed for this purpose questionnaire. The observed weaknesses in course topics have been eliminated and finally the modified course was uploaded to the university e-learning platform. Electrical engineering core course with $\mathbf{3 0 0}$ level was carried out for department students, where the obtained results shows significant enhancement in teaching and learning performances of both course instructors and students.

Index Terms-E-learning, Blinded learning, On-line learning, WEB based learning.

\section{INTRODUCTION}

The development and increasing growth of the Internet has provided new opportunities for delivering instruction and has allowed educators to offer courses in a more convenient and flexible environment [1-4]. In countries around the world, the widespread penetration of the Internet has increased the demand for courses to be offered online, and many organizations and institutions are now offering entire educational programs over the web in a variety of fields[5,6]. Furthermore, offering on-line courses removes the challenges in form of geographical obstacles, boundaries and closers. E-learning courses in Occupied Palestinian Territories have been significantly grown up due to Israeli barriers, scattering the regions and therefore students inability to attend classrooms. This issue forced university academics in Palestine to look for alternative teaching strategy that overcomes aforementioned obstacles [7-9].The unique solution was developing an e-learning courses in various engineering, humanities, health sector, business , i.e. The designed e-learning course entitled " Introduction to Electrical machines" was carried out during 2008/2009 academic year.

Experience has shown that online courses can provide the same opportunities for the teaching and learning process as those associated with traditional classrooms but only if teachers learn and apply new teaching skills and if their courses are designed with online delivery in mind. Online teachers need a variety of talents and abilities. Some distance education courses require the teacher to be course planners, instructional designers, technical experts, writers, or editors and troubleshooters when technical equipment fails $[9,10]$. These skills are not part of teaching in the traditional sense of the word, but may be necessary in online education.

\section{Research Methodology}

\section{A. Course Requirements:}

Design and implementation of an e-learning course is complicated pedagogical process that depending on large numbers of factors and requirements affecting design level, course quality and expected teaching outcomes. Figure1 illustrates the overall view of parameters that affects successful design of e-learning course, where the most important factors and requirements are as follows:

- Educational institution character: depending on the institution character, there are three major characters in Palestinian educational systems: Institutions with regularly attendance, with blended attendance and with distant and on-line learning.

- Student target group: in form of their academic level, freshman, undergraduate, or graduate students.

- Course character: pure theoretical courses have different e-learning approach with respect to courses having both theoretical and practical parts. Furthermore, the character of the course dictates the suitable e-learning methodology.

- Technical infrastructure: the existing infrastructure in form of internet and intranet performances, applied learning management system (LMS) [11], ease of student access to the e-learning portal.

- Communication skills of targeted learners are the most affecting factors, and must be taken into consideration in design and building of e-learning course. Student's communication weaknesses are treated and eliminated before involving students in learning process.

- Educators experience and readiness: Similar to student's readiness, course educators should have good experience in selecting suitable learning methodology, education tools, proposing fair evaluation system, good knowledge in multimedia \& graphics design, and ability to conduct continuous development of proposed courses. 


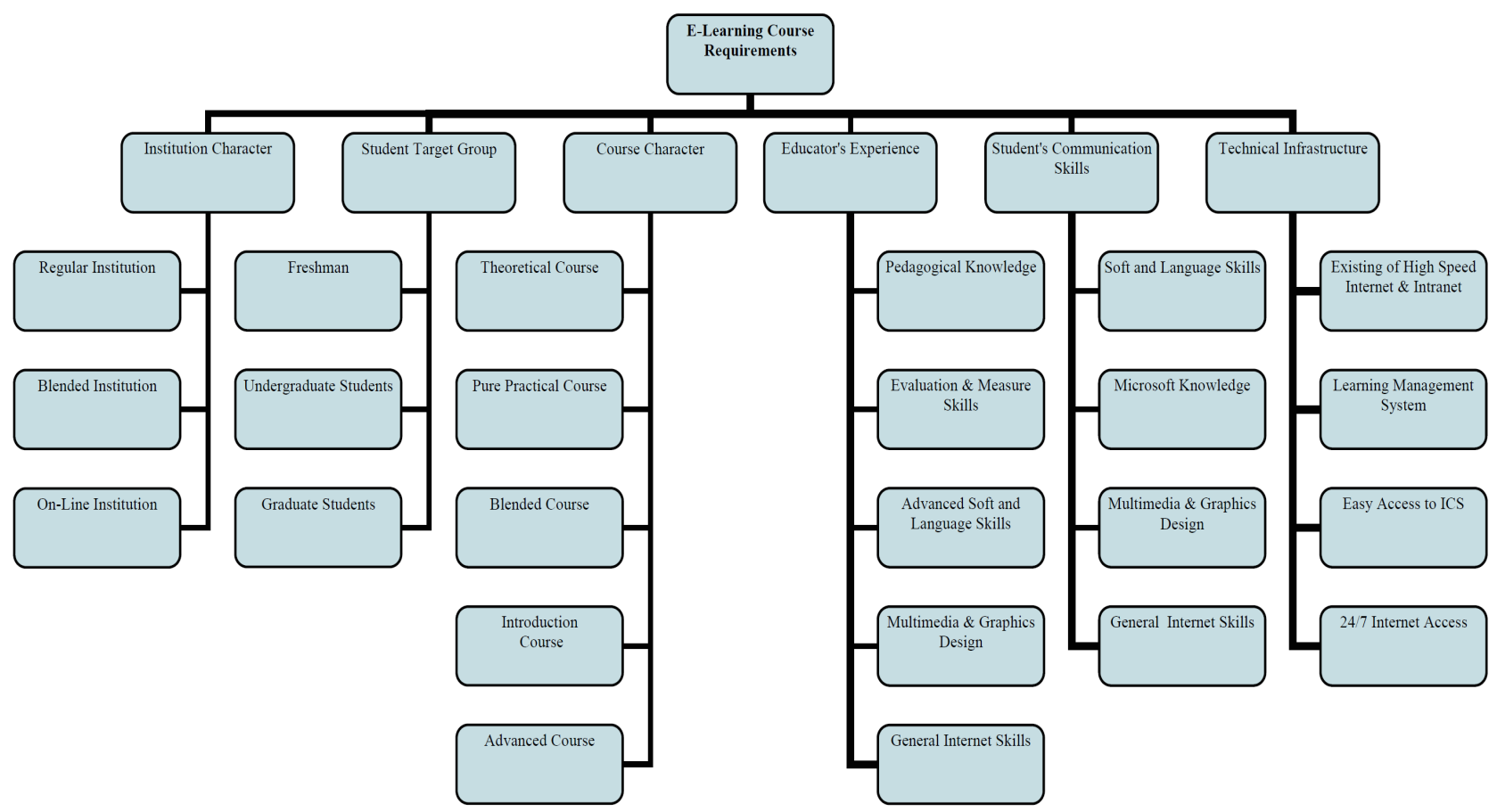

Figure 1. E-learning course hierarchy

\section{B. Students' evaluation needs}

According to fig.1 the e-learning course hierarchy and dependency is illustrated where the acting factors are clearly defined, studied and processed. The present paper describes concrete case study with the following input parameters:

- The course in conducted in regularly university, where the e-learning course is applied as supporting educational source.

- The targeted group is under graduated students in department of Electrical \& Computer Engineering / College of Engineering \& technology at PPU.

- The course character is introductory course entitled "Introduction to Electrical machines" as department compulsory course.

- Educational experience, the course instructors have good knowledge in information communication technology (ICT), graphics design and long-term teaching experience, so they have advanced knowledge in pedagogical issues and course measures.

- The university infrastructure in the field of ICT to some extend satisfied the educational system requirements.

- Students communication skills: This task presents challenge for successfully designing and offering high quality e-learning course, because of the following factors:

- Large variety of students knowledge in ICT , therefore it is difficulty to offer course with predetermined ICT requirements before eliminating students weaknesses...

- Student financial shortages, some of attended students are with financial shortage in having high speed internet access at home in additional to absent of high performance computer unit.
- Communication and language skills: these skills are mandatory condition for successfully conducting teaching-learning process.

Therefore eliminating students ICT skills weaknesses requires conducting several types of field surveys such as skills requirement questionnaire and direct student interviews aiming at evaluating their specific needs and how these needs can be realized.

\section{Student requirement analysis}

Student requirements analysis can be formulated as follows:

- Identify the needs of the participants/ attendee to the proposed Course.

- Create an appropriate toolset for data collection.

- Data gathering and analysis about the final target group.

- Create specific training activities which meet the identified needs of the participants and help developing the use of knowledge information and learning technologies in the university.

Figure 2 illustrates the questionnaire structure used for data gathering, analysis and specifying students' needs.

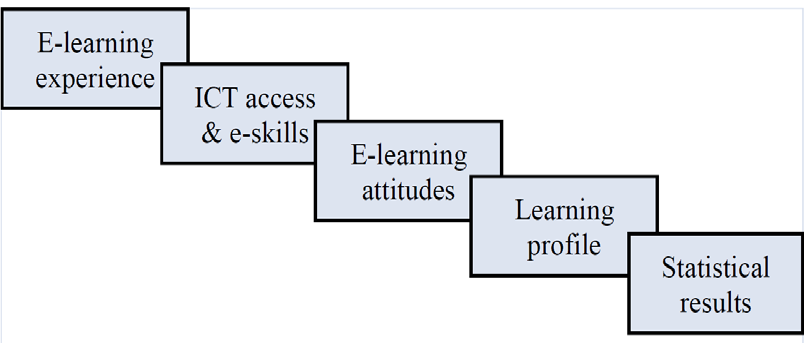

Figure 2. Structure of the questionnaire 


\section{COURSE DESIGN}

This course was designed as a result of two-years learning program sponsored by European Union [12,13] where various learning modules and management systems have been discussed and implemented during conducted training process in Italy. As result of this international activity this course was selected for design and being offered for PPU's students.

Taking into account the proposed structure of conducted questionnaire, the applied methodology in building the proposed course is illustrated in fig. 3 in form of functional flowchart, where several components are designed and implemented in predetermined manner with purpose fulfilling the course requirements and macro objectives. Three major tasks:

- Course Performance Analysis and Outcomes

- Students skills requirements

- Storyboard \& evaluation system design.

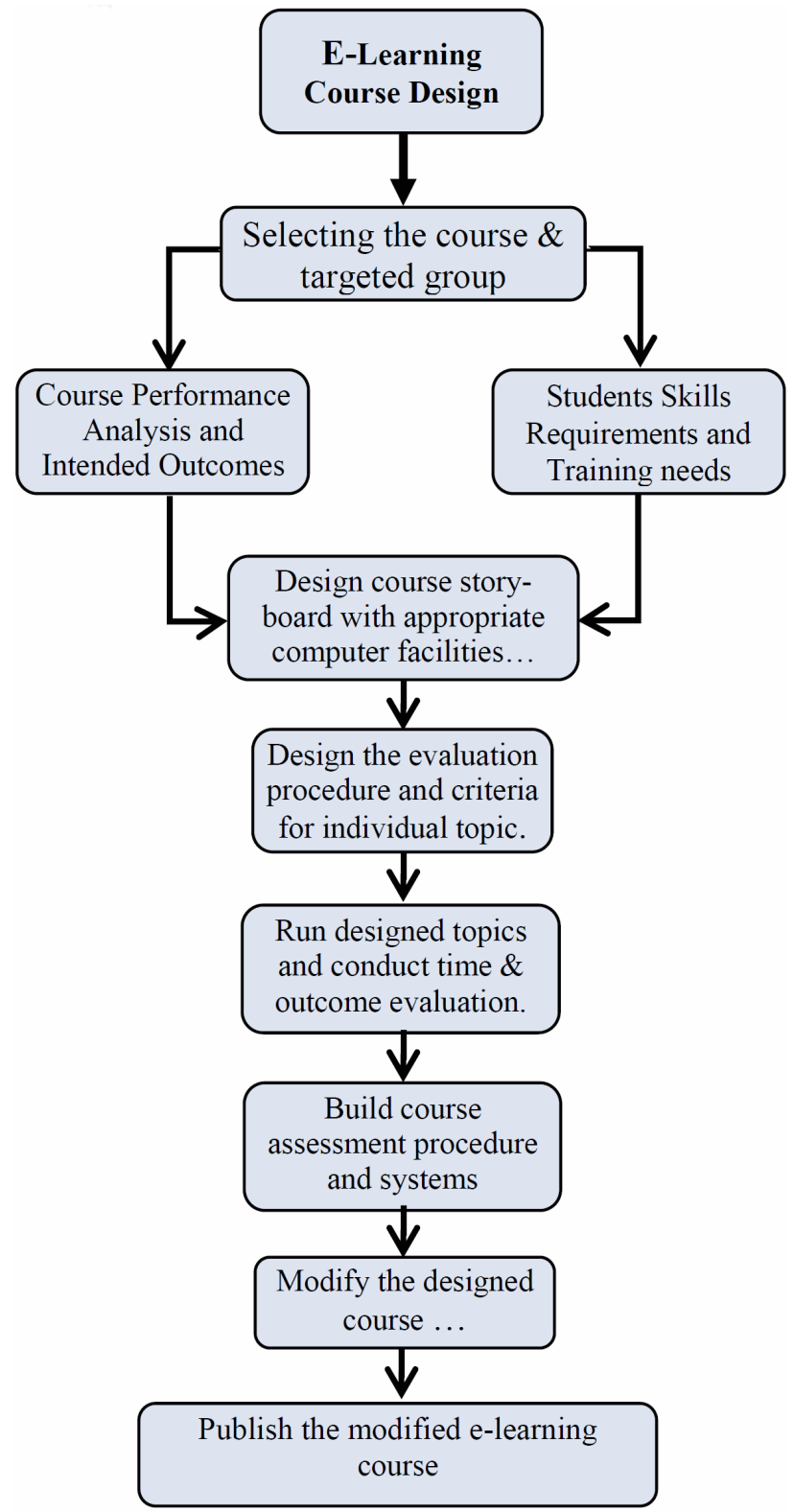

Figure 3. Functional diagram of designed course.

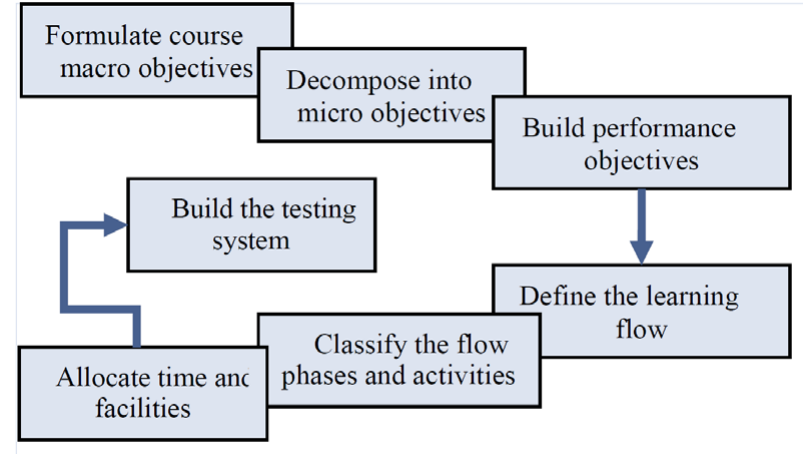

Figure 4. Course outcomes and performance analysis.

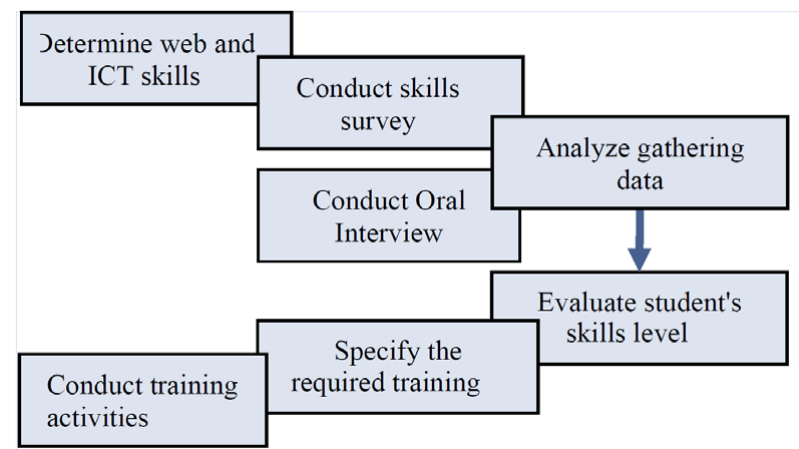

Figure 5. Functional diagram of student's skills requirements.

\section{A. Course performance analysis \& outcomes}

Course performance analysis and ILOs are the most important tasks when e-learning course is selected for design. The functional block diagram depicted in fig. 4 illustrates the sequence of determining performance analysis and intended outcomes.

\section{B. Students skills requirements}

Figure5 illustrates functional diagram of student's skills requirements evaluation, where two kinds of evaluation have been conducted, skills survey in form of written questionnaire and oral interviews with participants in the course. The purpose of this activity is to determine students ICT knowledge level and their training needs.

The conducted skills survey covers the most important 16 tasks (questions) with different characters which related to students ICT knowledge level, infrastructure and students language and communications capabilities. Some of these questions are stated as follows:

Q1. Are you good involved with internet and web applications?

a.I have satisfied internet skills and web applications

b.I have some weaknesses in internet skills and web applications

Q2. Have you been involved in e-learning course?, ( please you can choose more than one answer)

a. I have experience with e-learning course as learner I

b. I use e-learning as a trainer for my own trainings

c. I have been involved in e-learning as an instructional designer, developing e-learning course.

d. I am involved with e-learning as a manager in my organizations 
Q3. Have you good internet access at home?

a. Yes, I have good internet performances.

b.Yes, I have, but I prefer to use the university computer labs.

c. No, but I can use the university computer labs.

Q4. With which kind of e-learning tools have you made experiences so far? I have experience with learning....... (Several choices are possible).

a. Using a multimedia CD-Rom for self study purposes

b. In a Web based e-learning course without face-to-face sessions.

c. In a web based e-learning course with fact-to-face sessions.

d. Using the internet for learning purposes.

Q5. The following statements describe general ICT skills. Please choose the most suitable answer for you?.( only one answer possible)

a. I have the basic computer skills (create text, file, saving,)

b. I have the basic skills for finding my way around the Internet.

c. I can send an email with a file attached

d. I can carry out an online conversation with others using the Internet. i.e.

The obtained results of conducted survey for above mentioned questions are illustrated in fig.6, where it is shown that enrolled students have extremely different ICT knowledge levels which complicate successfully conducting e-learning course. Furthermore additional training activities must be offered for students suffering from deep weaknesses in ICT knowledge. Training program has been designed and conducted for students enrolled in this course.

\section{Design topic's storyboard}

Course storyboard is useful activity for design elearning course topics, it presents the required interactive tools, techniques, animations, images, and interpretation of the topic content aiming at achieving the planed teaching objectives and outcomes. Figure7 illustrates storyboard design procedure.

\section{Assessment evaluation}

For the designed course an evaluation system should be designed taking into account various activities applied in course topics.

Since the on-line character of the course, the applied assessment procedure relays mainly on time-free assessment and self motivation tools. Figure 8 illustrates functional flowchart of applied assessment procedure.

As a case study, the applied assessment procedure for elearning course in the field of electrical machines has the grading system shown on table 1 , where students interactive and critical thinking activities occupies $50 \%$ of total grade, which is major advantages of proposing e-learning course.

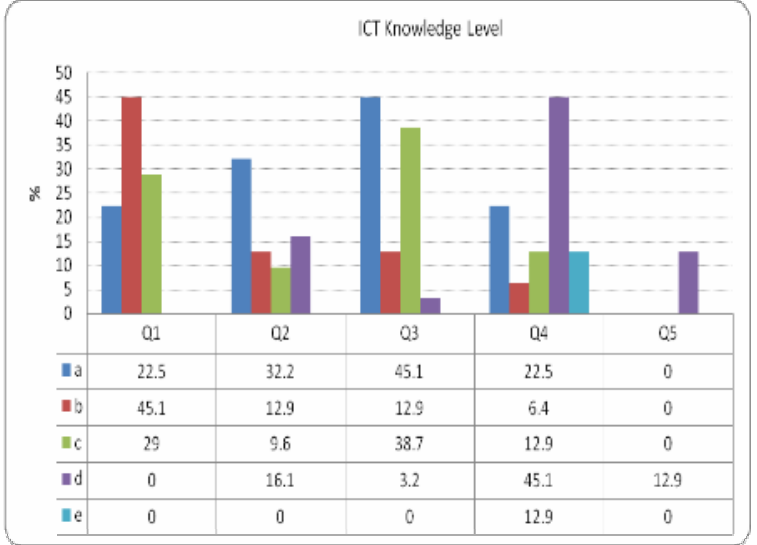

Figure 6. Survey results of illustrated questions.

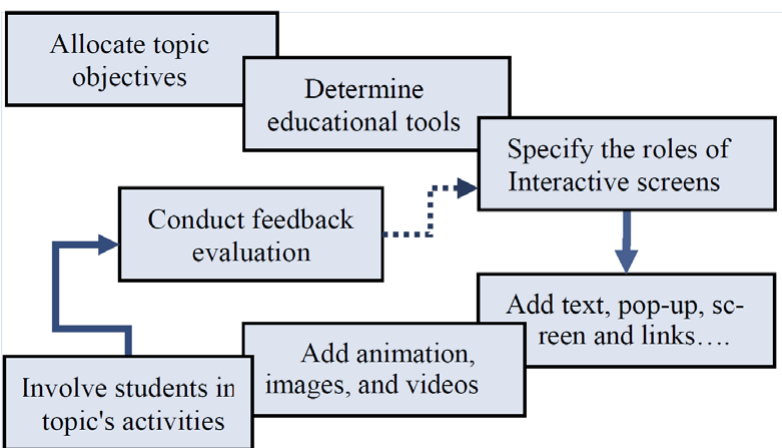

Figure 7. Storyboard design procedure

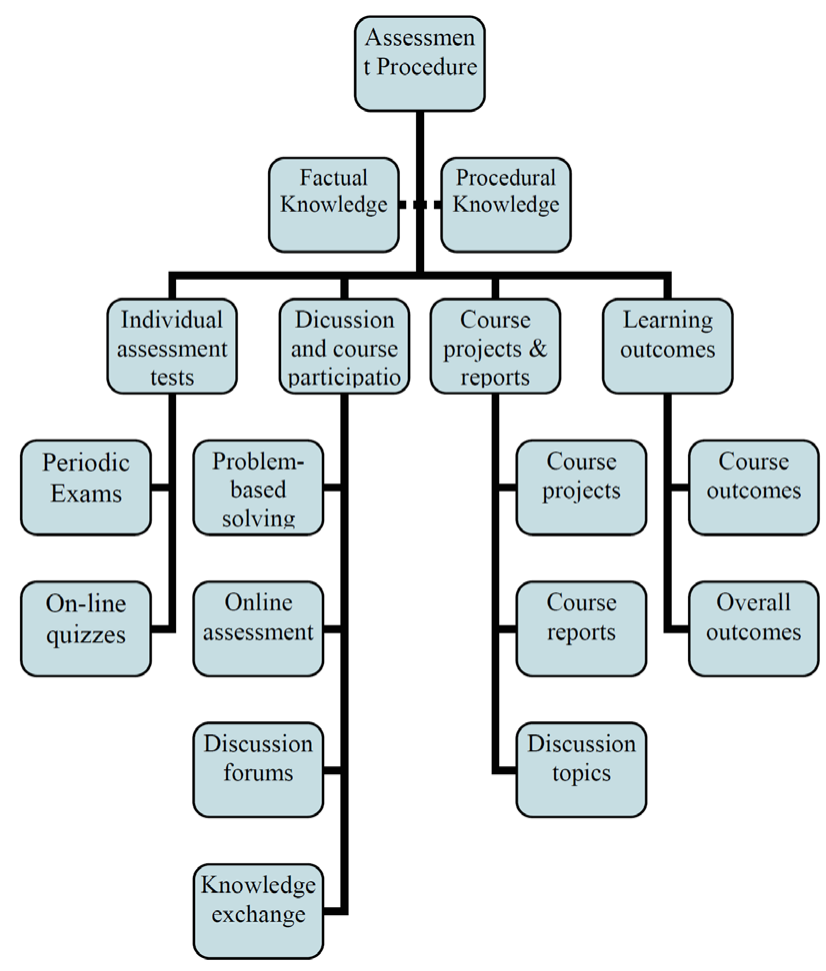

Figure 8. Course assessment procedure 
TABLE I.

CONCRETE GRADING SYSTEM OF DESIGNED COURSE

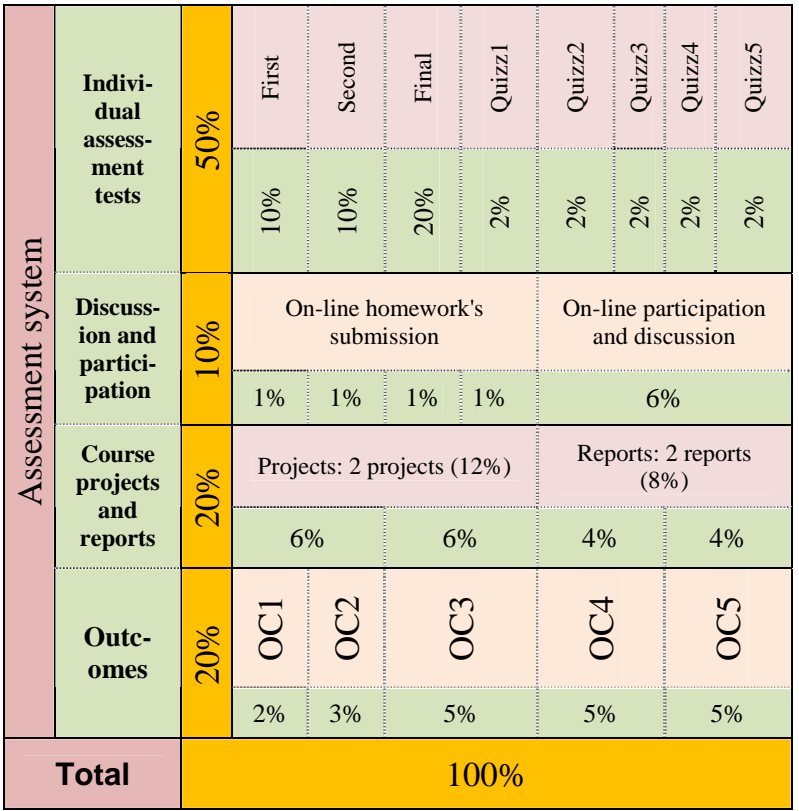

\section{E. Design the course evaluation questionnaire}

After completely design of e-learning course there is a need of overall course evaluation with respect to topics, educational tools, allocated time and finally the achieved intended learning outcomes. Realizing these tasks requires two evaluation procedures:

\section{1) Expert and department evaluation}

Expert and department evaluation aiming at providing course instructor with quality feed back with respect to educational quality, course content, outcomes, and allocated time. Figure 9 presents course evaluation chart.

2) Students evaluation :

Student's evaluation feedback presents key factor for successfully conducting of e-learning course. Because of that, it's worthy to get evaluation feedback from targeted group involved in this course. Figure 10 illustrates some of evaluation results, where 45 students have been questioned and interviewed.

The following questions have been assigned:

Q1- Are the proposed course topics good prepared and arranged?

Q2-Is the proposed management system simple and friendly used?

Q3- Is the course content good designed with appropriate flow?

Q4- Do you face difficulties when browsing the required learning data?

Q5- Is there a variety in used learning tools and methodologies?

Q6- Is there a variety in evaluation system?

Q7- Is the proposed evaluation system exactly measure student knowledge?

As shown from fig.10 expert's and student's evaluation results gave clear feedback for further modification of elearning course to be more motivated, with innovative educational tools, and more concentration over students teamwork and collaborative activities.

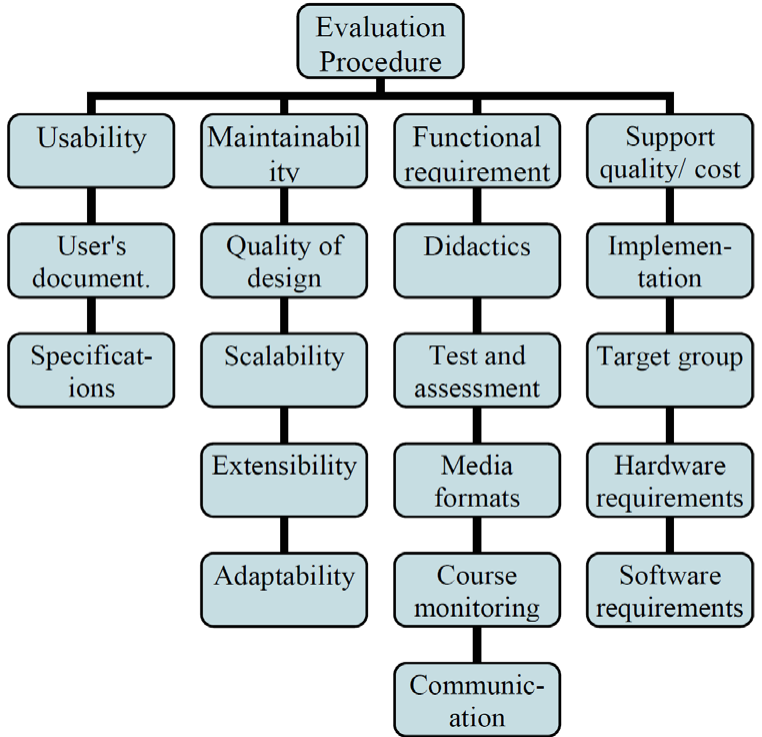

Figure 9. Expert course evaluation chart.

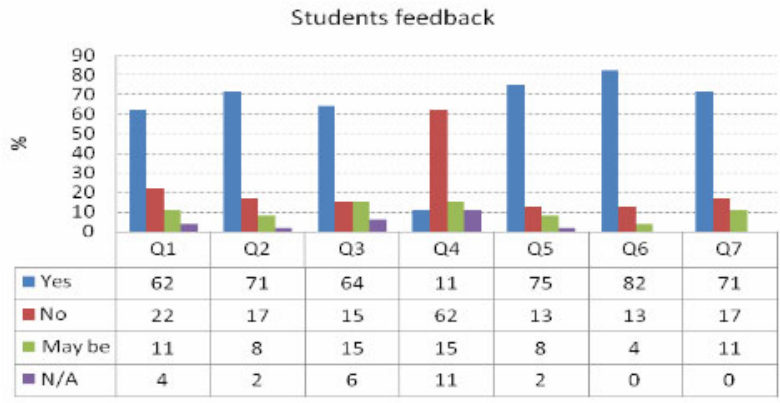

a) Issues related to course management \& evaluation
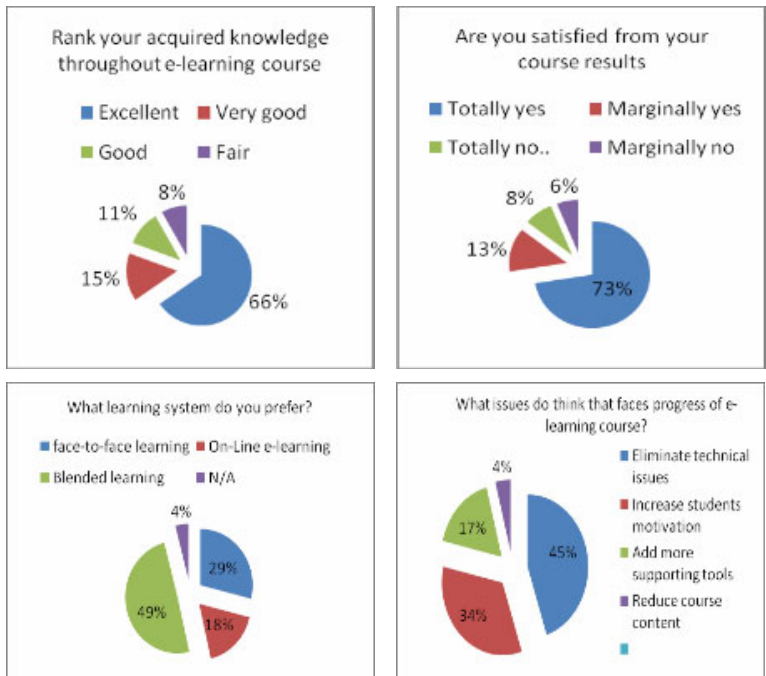

What issues do think that faces progress of $\mathrm{E}-$ leaming course?
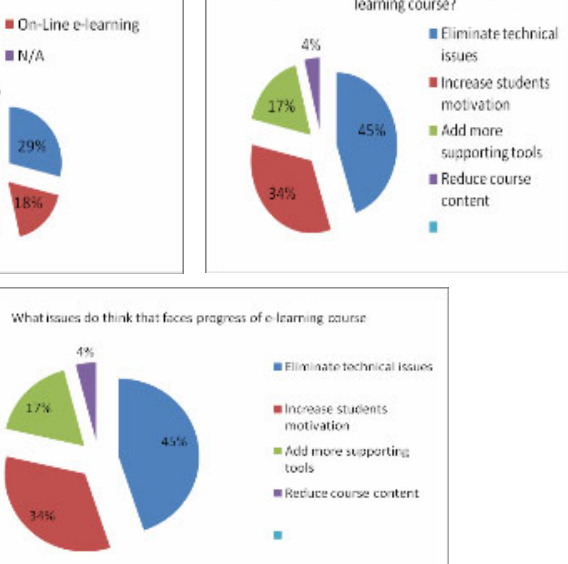

b) Issues related to e-learning development strategy. Figure 10. Student's evaluation and feedback. 


\section{CONCLUSION}

The following conclusion can be drawn when designing e-learning course:

- Information communication technology estimating questionnaire is necessary for evaluation the student knowledge level.

- Designing e-learning course depends on course character and student targeted group

- The designed learning tools must take into consideration student's needs, educational level and course character.

- The designed course should be evaluated from both experts and involved in educational process students.

- Despite the evaluation results of field experts, students' evaluation results must taking into consideration in modifying course content and educational tools.

- Student's feedback differs from one issue to another, with respect to course management and evaluation which ranges between $62 \%$ to $82 \%$, which means further efforts are needed in design e-learning course.

- With respect to gained knowledge and satisfaction, elearning strategy presents optimized solution for future learning strategy.

- Despite the observable benefits of applying elearning course, students prefer blended learning rather than pure on-line e-learning. This is because changing student's educational mentality takes long time to be changed.

- As a result of aforementioned design procedure, first author was selected for teaching excellence award among Palestinian Universities offered by American Agency AMIDEAST-USAID [14] for his efforts in design and implementation of this course.

\section{REFERENCES}

[1] Downes S.; "Models for Sustainable Open Educational Resources", Interdisciplinary Journal of Knowledge and Learning Objects, Volume 3, 2007

[2] Garbett C., "Value from information systems. Return on investment"; e-learning compared to campus-based learning, Interactive Technologies Conference. Society of Applied Learning Technology, 2004.

[3] Barry W. (2003) Distance Education at a glance, Paper available in http://www.uidaho.edu/eo/distglan.html

[4] Olaf Zawacki-Richter; "Online Faculty Support and Education Innovation - A Case Study", European Journal of On-Line learning, 2005, Vol.2. Paper available in http://www.eurodl.org/ ?article $=163$

[5] Carr, M.;" The Shallows: What the Internet is doing to our brain"; New York, London: W.W.; Norton \& Company, 2010.

[6] Daniel J.; "What is an Open University'? http://www.col.org/ resources/speeches;/2007presentations/Pages/2007-0111.aspx, June, 2011.

[7] Joan Mateo," Designing online learning assessment through alternative approaches: facing the concerns"; European Journal of Open, Distance and E-Learning; 2010; http://www.eurodl.org/ ?article $=294$
[8] Dougiamas M. \& Taylor, P. (2003) Moodle: Using Learning Communities to Create and Open Source Course Management System, World Conference on Educational Multimedia, Hypermedia and Telecommunications, 2003 (1), 171-178.

[9] Reeves T.C.; "Alternative Assessment Approaches for Online Learning Environments in Higher Education", Journal of Educational Computing Research, 23, 1,pp. 101-111. http://dx.doi.org/10.2190/GYMQ-78FA-WMTX-J06C

[10] Microsoft Research External Research and Programs. The Future of Information Technology -Growing the Talent Critical for Innovation. Microsoft Faculty Summit Report 2006. Redmond, USA.

[11] Moodle learning management systems. http:/moodle.net

[12] MEDA-ETE;" Inventory of good e-learning practices"; Component Four-, e-learning Project; March, Sestri- levanti, Italy, 2007.

[13] MEDA_ETE Regional Project/Component Four/ e-learning Project, Turin, Italy, 2008. http:// www.meda-ete4elearning.eu.

[14] Teaching Excellence Colloquium, 26-27/June, 2008, organized by AMIDEAST-USAID, Bethlehem, Palestine.

\section{AUTHORS}

SAMEER KHADER is an Associate Professor of Electrical and Computer Engineering at Palestine Polytechnic University (PPU) - Palestine. During the 20102011 year he was a visiting professor at the University of Hartford, CT, USA spending his sabbatical year. He is a director of Power Electronics \& Signal Processing Research Unit at PPU. Before that he served for ten years as university academic provost, dean of college and Chair of the Electrical \& Computer Engineering Department at PPU. His research interests include Electrical machines, Electrical drives, Power Electronics Converters, Renewable Energy Sources and Smart Grids, in addition to engineering education. He has several publications in international journals and conferences. Dr. Khader may be contacted at sameer@ppu.edu

AKRAM ABU-AISHEH is an Associate Professor of Electrical and Computer Engineering at the University of Hartford where he has served as the assistant chair of the Electrical and Computer Engineering Department and director of the electronic and computer engineering technology program for two years. Professor Abu-aisheh has a doctorate in Optical Communications from the Florida Institute of Technology and Master of Science and Bachelor of Science degrees in Electrical Engineering from the University of Florida. Professor Abu-aisheh has ten years of industry experience in the US including five years as a senior member of the technical staff at Tyco Telecommunications. His research interests include Fiber Optic Communications, Solar Energy, Power Electronics, and Engineering Education. He has published a book, a book chapter, and several international journals and conference papers. Dr. Abu-aisheh may be contacted at abuaisheh@hartford.edu

This article is an extended version of a paper presented at the International Conference EDUCON2012, held April 17 - 20, 2012, in Marrakesh, Morocco. Received 28 April 2012. Published as resubmitted by the authors 21 July 2012. 